The University of Maine

DigitalCommons@UMaine

Scientific Articles

Publications

Spring 5-24-2012

\title{
Out-of-season gamete production in Strongylocentrotus droebachiensis: Photoperiod and temperature manipulation
}

NIcholas Brown

Stephen Eddy

Nichole T. Kirchhoff

Follow this and additional works at: https://digitalcommons.library.umaine.edu/ari_articles

\section{Repository Citation}

Brown, NIcholas; Eddy, Stephen; and Kirchhoff, Nichole T., "Out-of-season gamete production in Strongylocentrotus droebachiensis: Photoperiod and temperature manipulation" (2012). Scientific Articles. 4.

https://digitalcommons.library.umaine.edu/ari_articles/4 


\title{
Out-of-season gamete production in Strongylocentrotus droebachiensis: Photoperiod and temperature manipulation
}

\author{
Nicole T. Kirchhoff* , Stephen Eddy, Nicholas P. Brown \\ Center for Cooperative Aquaculture Research, University of Maine, Franklin, ME 04634, USA
}

\section{A R T I C L E I N F O}

Article history:

Received 13 November 2009

Received in revised form 19 February 2010

Accepted 2 March 2010

\section{Keywords:}

Spawning

Gametogenesis

Photoperiod

Sea Urchin

Temperature

Strongylocentrotus droebachiensis

\begin{abstract}
A B S T R A C T
The natural spawning of Strongylocentrotus droebachiensis is limited to late winter into early spring. In order to reduce the cost of urchin production, out-of-season gamete production is necessary. This study attempted to condition broodstock for out-of-season gamete production through the use of two different photoperiod and temperature regimes: a Constant Spring and an Advanced year; hypothesized to induce maturation through suspension or advancement of the gametogenic cycle, respectively. Viable gametes were successfully produced out-of-season with fertilization and hatch rates equal to or surpassing the levels recorded for wild urchin's in-season. In addition, specific fecundity was significantly higher in out-of-season conditioned urchins compared to the in-season wild urchins. Histological techniques proved that gametogenesis was both suspended and advanced through manipulation of the photoperiod and temperature. In addition, several important observations were made regarding reproductive physiology in the green sea urchin, the implications of which are important to the economic development of the green sea urchin aquaculture industry and management of wild stocks.
\end{abstract}

(c) 2010 Elsevier B.V. All rights reserved.

\section{Introduction}

Out-of season conditioning of sea urchins began in the 1960s (Fuji, 1967 ) in an attempt to increase market value through enhanced gonad yield. While gonad enhancement is an important step towards the development of sea urchin aquaculture, economical gamete production is also necessary (Harris et al., 2003; Luis et al., 2005; Walker et al., 1998). Research began on out-of-season gamete production in the green sea urchin, Strongylocentrotus droebachiensis (O.F. Müller, 1776) in the 1990s (Walker et al., 1998). However researchers have so far been unsuccessful in promoting out-of-season vitellogenesis and gamete production in this species.

One of the biggest hindrances to aquaculture development of the green sea urchin is the seasonality of natural spawning, which limits production to between four and seven months a year. Annual spawning of $S$. droebachiensis typically occurs in the spring, from February to May (Cocanour and Allen, 1967; Falk-Peterson et al., 1983; Himmelman, 1978; Larson et al., 1980; Meidel and Scheibling, 1998a; Munk, 1992; Oganesyan, 1998; Vadas et al., 1989). In central and northeastern Maine, where this study occurred, peak spawning takes place in March (Vadas and Beal, 1999), yet urchins can be induced to spawn from late-January to early-July (Oganesyan, 1998).

\footnotetext{
* Corresponding author. Tel.: +1 61488474304; fax: +1 61363243804 . E-mail address: Nicole.kirchhoff@umit.maine.edu (N.T. Kirchhoff).
}

The ability to manipulate spawning season would enable commercial sea urchin hatcheries to utilize facilities more efficiently.

The trigger of gametogenesis, and more specifically vitellogenesis, for $S$. droebachiensis is still under debate and has been intensely researched in recent years. Since each species of sea urchin has been found to have its own environmental or chemical cue, this field is still extremely underdeveloped. Three environmental factors are universally cited as important to the reproductive cycle: diet, photoperiod, and temperature (McBride, 2005). Giese (1959) was the first to suggest photoperiod to be a control of gametogenesis. It has been determined that short days (or the autumnal equinox) in the annual cycle are what triggers the initial stage of gametogenesis in some species such as Strongylocentrotus purpuratus (Bay-Schmidt and Pearse, 1987; Pearse et al., 1986), S. droebachiensis (Dumont et al., 2006; Walker et al., 1998), and Eucidaris tribuloides (McClintock and Watts, 1990). Walker and Lesser (1998), using the autumnal equinox equivalent photoperiod, produced mature $S$. droebachiensis males, but failed to produce mature females. Subsequently, they suggested that temperature is an important modulator of vitellogenesis in green sea urchins (Walker and Lesser, 1998). Wild observations on S. droebachiensis suggest that gametogenesis coincides with a drop in temperature from mid-December to January and spawning correlated with the rapid rise of seawater temperature in the spring (Stephens, 1972; Vadas et al., 1999). Seawater temperature has been found to be an important cue for out-of-season gametogenesis in some sea urchin species: Anthocidaris crassispina (McBride, 2005), Hemicentrotus pulcherrimus, and Pseudocentrotus depressus (Yamamoto et al., 1988). Each of these species lives in areas with large annual 
fluctuations of seawater temperature (Sakairi et al., 1989; Yamamoto et al., 1988) much like the green sea urchin of Maine. A highly nutritious diet is also important for successful gametogenesis in S. droebachiensis (Ebert, 1968; Lemire and Himmelman, 1996; Minor et al., 1997; Thompson, 1982; Vadas, 1977), including various species kelp, their preferred diet (Ebert, 1968).

This study describes attempts to achieve out-of-season gamete production in S. droebachiensis using two different photoperiod/ temperature manipulations. The first follows research on Paracentrotus lividus (Luis et al., 2005), using Constant Spring conditions of central to northeastern Maine: $12 \mathrm{~L}: 12 \mathrm{D}$ and $6 \pm 0.3^{\circ} \mathrm{C}$. It was hypothesized that this technique should maintain the ripe condition of both males and females indefinitely, without triggering a new cycle of gametogenesis. The second conditioning treatment employed an Advanced regime, altered so that by mid November, the apparent photoperiod and temperature will be that of mid April, i.e. advancement of 6 months. It was hypothesized that this second technique should stimulate premature initiation and completion of gametogenesis in both sexes.

\section{Materials and methods}

\subsection{System design}

Two separate broodstock conditioning systems were designed and constructed, each with a separate water-treatment system contained within a $10^{\prime} \times 9^{\prime}$ insulated, light proof enclosure. Each system consisted of $4 \times 1001$ holding tanks, a $2 \mathrm{~m}^{3}$ sump/moving bed biofilter with plastic media, a $3 / 4 \mathrm{HP}$ circulating pump, a $35 \mu \mathrm{m}$ cartridge filter, and a $40 \mathrm{~W}$ U.V. sterilizer. Lighting for each system was provided by an 8 ' double fluorescent, T1 daylight fitting $\left(0.580 \mathrm{~W} / \mathrm{m}^{2}\right)$ fitted with electric timers to control the photoperiod. Each system was also thermostatically controlled with a $1 \mathrm{~kW}$ heater and a $1 \mathrm{HP}$ chiller. Water flowed into each holding tank via a spray bar mounted at one end of the tank and left via a surface drain at the other end. From the holding tanks, water drained directly into the aerated biofilter below, then pumped through the heater/chiller system, through the cartridge filter and U.V sterilizer before returning to the holding tanks. Mortality, water temperature, and dissolved oxygen were measured daily and water quality parameters (dissolved ammonia, nitrite, nitrate, $\mathrm{pH}$, alkalinity, and salinity) were assessed weekly.

\subsection{Establishing the photo-thermal conditioning regime}

From March 1st to 15th 2006, each conditioning system was stocked with reproductively ripe wild adult ( $>40 \mathrm{~mm}$ test diameter) S. droebachiensis. Two hundred and seventy four urchins with a mean test diameter of $66.4 \pm 1.0 \mathrm{~mm}$ were stocked into the Constant Spring system (Constant Spring group 1) and 251 urchins with a mean test diameter of $64.4 \pm 1.1 \mathrm{~mm}$ were stocked into the Advanced system (Advanced System Group). The urchins were obtained by divers from three locations in Penobscot Bay, Maine, during a typical commercial harvest. Urchins were collected from a variety of bottom types, kelp, cobble or ledge, at depths between 5 and $15 \mathrm{~m}$. They were transported moist to the Center for Cooperative Aquaculture Research (CCAR) within $2 \mathrm{~h}$ from landing at the dock and were randomly distributed among the two conditioning systems. After a one month acclimation period, the Constant Spring system was held at a constant photoperiod of $12 \mathrm{~L}: 12 \mathrm{D}$ and a temperature of $6{ }^{\circ} \mathrm{C} \pm 0.3{ }^{\circ} \mathrm{C}$. The Advanced system received an advanced photoperiod and temperature regime adjusted so that by the 19th of November 2006, the apparent ambient temperature and photoperiod would be similar to that of the 10th of April in the northeastern Gulf of Maine, i.e. an advancement of 6 months (Fig. 1). An additional 50 urchins were stocked into the Constant Spring system in March 2007 and conditioned in the same method (Constant Spring group 2). The urchins were fed to satiation weekly with fresh, locally harvested kelp (75\% Laminaria saccharina,
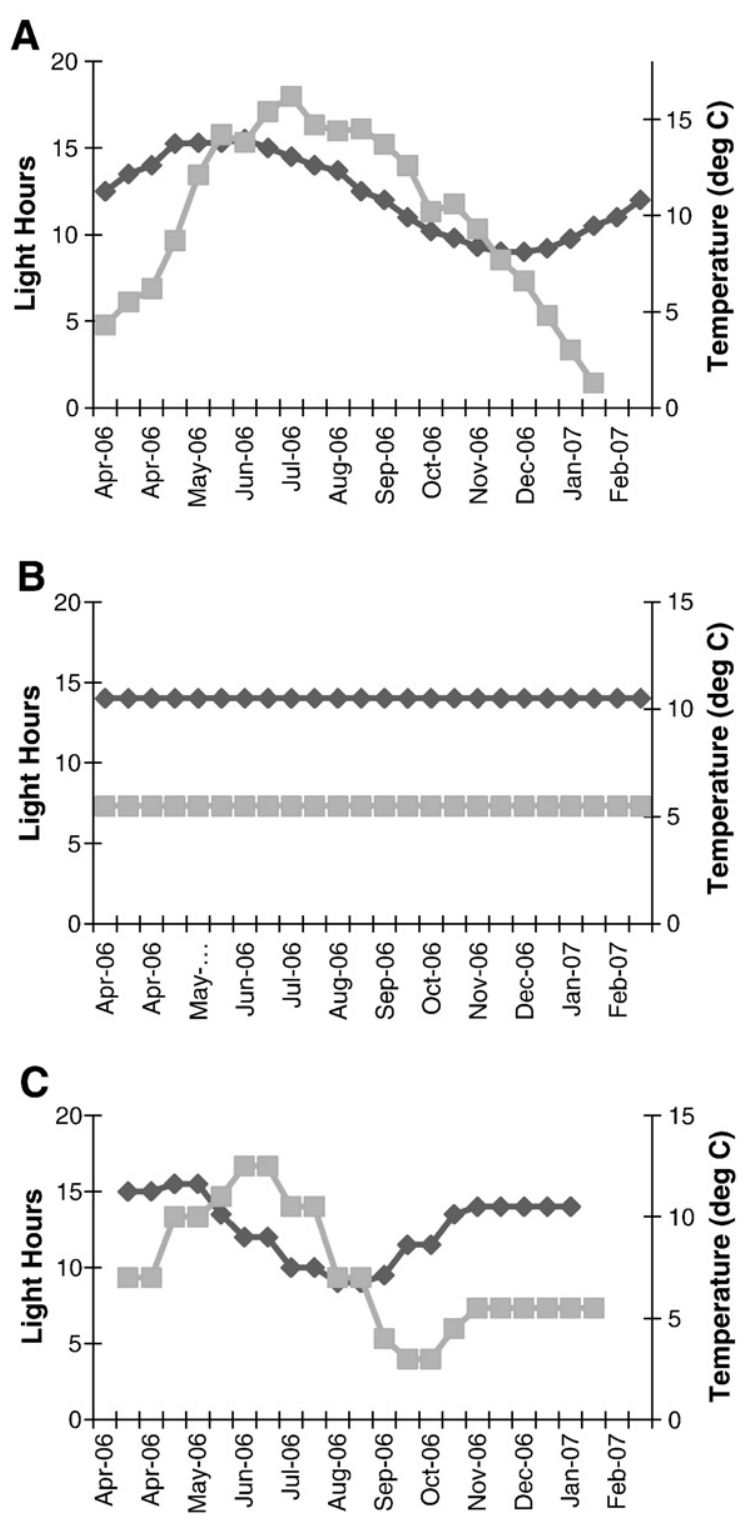

Fig. 1. Photoperiod and temperature conditions. (A) Ambient conditions in Penobscot Bay (B) Constant Spring conditioning system and (C) Advanced conditioning system. Temperature is denoted in grey, light hours in black.

15\% Laminaria digitata, and 10\% Ulva lactuca; approximately 10\% dry matter), about $4.5 \mathrm{~kg}$ wet weight per system per week. Fecal pellets were siphoned biweekly and tank sides scoured twice per month in each conditioning system.

\subsection{Sampling}

Samples were taken periodically from each system and from the field for morphological examinations, spawning trials, and histology/ stereology (Table 1). For all samples, test diameter was measured using a ruler to the nearest $0.1 \mathrm{~mm}$ and the total body weight was measured to the nearest $0.1 \mathrm{mg}$. In addition, gonad weights were collected on all spawning and histology samples. The gonads were removed, rinsed with saltwater, blotted dry, and weighed to the nearest $0.1 \mathrm{mg}$. Whereas gonad weights and derived gonad indices are affected by test diameter, standardization needs to be performed prior to analysis (Harrington et al., 2007). Adjusted gonad weight (AGW) was calculated. 
Table 1

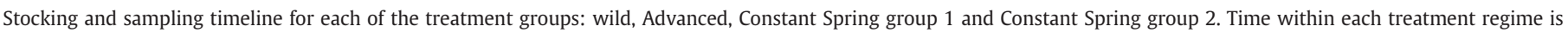
denoted through shading. H, histology/stereology; S, spawning; M, morphological. Sample size is denoted in parentheses.

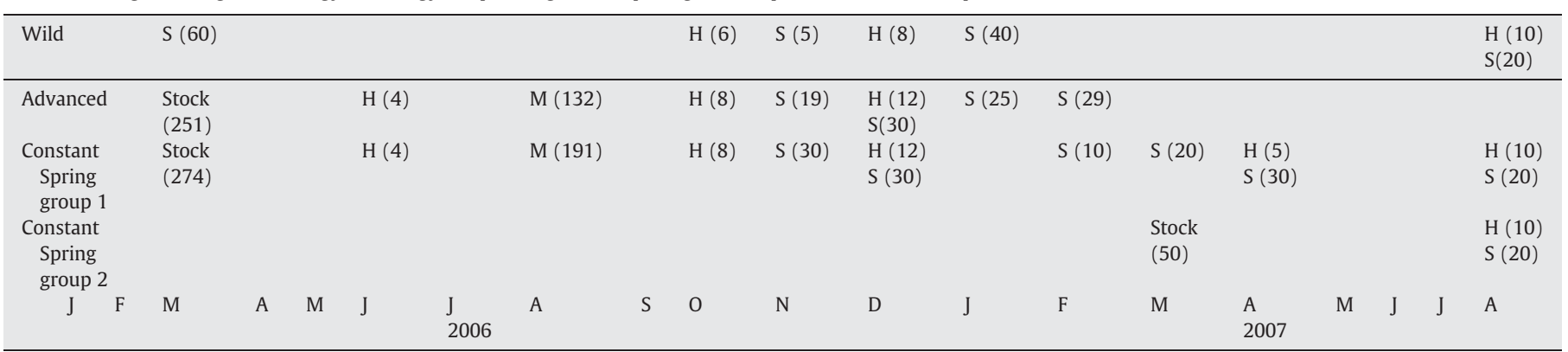

\subsection{Spawning trials}

Spawning trials occurred in March 2006 on a portion of the field collected urchins to assess the proportion of gravid urchins from the initial wild population. From November 2006 to August 2007 captive and field collected urchins were induced to spawn for out-of-season spawning trials according to the schedule shown in Table 1.

Standard spawning and fertilization techniques were used following Strathmann (1978). Urchins were removed from experimental systems and $2 \mathrm{ml}$ of $0.5 \mathrm{M}$ KCL was injected into the perivisceral cavity (Palmer, 1937) in a climate controlled, $10{ }^{\circ} \mathrm{C}$ room. Individual urchins remained dry, aboral side up, on a stainless steel laboratory bench and allowed to release gametes for up to $1 \mathrm{~h}$ post injection. Once gametes emerged from the madroporite and sex could be identified, females were turned upsidedown over room temperature $\left(10^{\circ} \mathrm{C}\right)$ porcelain cups for oocyte collection. Males were left aboral side up and sperm removed dry using a $1 \mathrm{ml}$ sterile syringe. For urchins which did not spawn, sex was determined through a wet mount of the gonad under a compound microscope $(400 \times)$. After $1 \mathrm{~h}$, oocytes were rinsed from the cups using $35 \mathrm{ppt}, 0.2 \mu \mathrm{m}$ filtered seawater, into a graduated cylinder. Eggs were allowed to settle for $5 \mathrm{~min}$ prior to volumetric measurement, which was taken to the nearest $1 \mathrm{ml}$. Volume of sperm was measured to the nearest $0.1 \mathrm{ml}$. Specific fecundity (i.e. $\mathrm{ml}$ spawn per g wet weight of urchin) was calculated for both sexes.

The viability of oocytes and sperm was determined through percent fertilization (i.e. formation of a fertilization membrane) and by percent hatch (i.e. development to the mid-blastopore stage). Oocytes from each individual female were placed in 11 of $35 \mathrm{ppt}, 0.2 \mu \mathrm{m}$ filtered natural seawater and fertilized with $0.1 \mathrm{ml}$ sperm diluted $10: 1$ with $35 \mathrm{ppt}$, $0.2 \mu \mathrm{m}$ filtered natural seawater. For oocyte volumes greater than $30 \mathrm{ml}$, $0.2 \mathrm{ml}$ sperm was used. After $10 \mathrm{~min}$, eggs were rinsed of excess sperm using a $64 \mu \mathrm{m}$ mesh sieve, and concentrated to a volume of $100 \mathrm{ml}$ using $35 \mathrm{ppt}, 0.2 \mu \mathrm{m}$ filtered seawater. After $1 \mathrm{~h}$, three $1 \mathrm{ml}$ samples were taken from the concentrated fertilized eggs, and the number of oocytes and fertilization rate calculated using a $1 \mathrm{ml}$ sample grid under a compound microscope $(100 \times)$. In addition, three $2 \mathrm{ml}$ samples were placed in three $100 \mathrm{ml}$ sterilized Petri dishes with $20 \mathrm{ml}$ of $35 \mathrm{ppt}$, $0.2 \mu \mathrm{m}$ filtered natural seawater and incubated in complete darkness at $9 \pm 0.5^{\circ} \mathrm{C}$. Dishes were removed after $72 \mathrm{~h}$ and percent hatch was calculated using a dissection scope $(40 \times)$.The paternal effect on oocyte viability was calculated for oocyte volumes greater than $8 \mathrm{ml}$. Each distinct female's oocyte was equally divided among three $1 \mathrm{l}$ beakers and fertilized with $0.1 \mathrm{ml}$ sperm from one of three individual males. Percent fertilization and percent hatch were calculated for each distinct mating.

\subsection{Histology and stereology}

Samples of gonads from both experimental and wild urchins ( $n=4$ to 12 individuals) were fixed in primary fixative (3\% glutaraldehyde in $0.2 \mathrm{M}$ sodium cacodylate buffer) and embedded in plastic following methods described by Walker (1980). Samples were sliced to $1 \mu \mathrm{m}$ and stained with aqueous $1 \%$ toluidine blue in $1 \%$ borax.

Histological analysis was performed using the techniques described by Walker and Lesser (1998). Each sample was identified as male or female and characteristic cells were identified. Nutritive phagocyte (NP) layer thickness was determined by measuring the total diameter of the NP layer from gonadal wall to gonadal lumen and then subtracting the diameter of germinal cells, if present. Measurements were taken to the nearest $0.01 \mu \mathrm{m}$. Oocyte size-frequency was calculated for each female sample by measuring the diameters of all oocytes containing a clearly visible nucleolus ( $n=10$ to 30 ). Oocyte measurements were taken under $200 \times$ magnification to the nearest $0.01 \mu \mathrm{m}$. Each sample was also digitally photographed under $200 \times$ and 400x magnifications. Photographs were used to determine the stage of reproduction following the classification scheme of Walker et al. (2005, 2001): Inter-gametogenesis and NP phagocytosis (spring), Pre-gametogenesis and NP renewal (summer), Gametogenesis and NP utilization (fall), End of gametogenesis, NP exhaustion and spawning (winter to early spring).

To obtain the relative volume fractions $\left(V_{\mathrm{v}}\right)$ of new or residual gametes, NP, and germinal epithelium, stereology was performed on each histological sample. A 64-grid compound microscope ocular piece under 400× magnification was used and cell type was characterized under each grid interception point, a total of 81 counts per slide. Relative volume fraction was calculated using the formula: $V_{\mathrm{v}}=$ \# intercepts of a particular cell type/total \# of intercepts.

\subsection{Statistics}

Comparisons of test diameter, whole wet weight, and gamete viability were completed between sample dates and systems using orthogonal design ANOVA. Fertilization and hatch rate were arcsine transformed prior to analysis. All spawning data was pooled for in-season (February thru April) and out-of-season (May thru January) for all statistical analyses. A one-way ANOVA was used to examine NP diameter, one test for each treatment and sex. Due to the allometric effect of test diameter on gonad weight, analysis of covariance (ANCOVA) was used to analyze the monthly difference in gonad weight for each treatment group by regressing gonad weight against test diameter (Harrington et al., 2007). Slopes were heterogeneous, therefore adjusted gonad weights (AGW) were calculated for each moth within each treatment group using the equation: $\mathrm{AGW}(\mathrm{g})=$ gonad weight $(\mathrm{g})$ - slope (within group mean of test diameter - between group mean of test diameter). One-way ANOVA was then performed on AGW between months for each treatment group and sex. A three factor polynomial trend line was then fitted to the data. One-way ANOVA was also used to assess stereology changes, with each treatment and sex separated prior to analysis. Volume fractions were arcsine transformed prior to analysis. Statistical analyses, assumed normality (Shapiro test, $p<0.05$ ), constant variance (Bartlett 
test, $p<0.05$ ), and were checked for the presence of outliers (Jack residuals and Cook's distance). When applicable, Tukey HSD post-hoc test was used to access differences at $p<0.05$. The $\mathrm{R} 2.31$ statistical package ( $\subset$ 2006. The R Foundation for Statistical Computing) was used and significance was assumed when $p<0.05$.

\section{Results}

\subsection{Survival and growth}

Survival over the nine month conditioning period was $56 \%$ in the Constant Spring system and $47 \%$ in the Advanced system. Mortalities occurred mostly in the first month post-stocking in the Constant Spring system (77\% of total mortalities), and within the first two months in the Advanced system (77\% of total mortalities). Mortalities declined rapidly with $>3 \%$ of the total mortalities occurring in either system occurring 4 months post conditioning. Stocking densities decreased from $75.22 \%$ surface area (SA) coverage to $42.28 \%$ SA in the Constant Spring system and from $76.87 \%$ SA to $36.45 \%$ SA in the Advanced system as urchins were removed for sampling or died during the experiment. In March 2007, 50 additional urchins (Constant Spring group 2) were stocked in the Constant Spring system at $54.41 \%$ SA. Stocking densities are presented as percent surface area coverage to account for differences in size of individual urchin test diameters and describe the amount of tank area available to each individual urchin (Kirchhoff et al., 2008).

In August 2006, after most of the mortalities had occurred, all urchins were morphologically measured. The Constant Spring urchins were found to have an average test diameter of $66.1 \pm 4.7 \mathrm{~mm}$; Advanced urchins averaged $64.0 \pm 9.8 \mathrm{~mm}$. No significant change in test diameter was found over the first year of conditioning in either system $(F=1.4841, d f=9,656, p=0.1498)$. Wet weight in August 2006 was $104.3 \pm 28.6 \mathrm{~g}$ in the Constant Spring system and $101.8 \pm$ $35.8 \mathrm{~g}$ in the Advanced system. Wet weight changed throughout the conditioning period in both systems $(F=2.0157, d f=9,656$, $p=0.03529$ ), as expected with change in reproductive conditioning. Neither test diameter $(F=1.4935, d f=7,385, p=0.1680)$ nor wet weight $(F=1.3422, d f=7,387, p=0.229)$ changed in the Constant Spring system group 1 when examined over the extended eighteen months of conditioning.

Constant Spring group 2 urchins averaged $65.8 \pm 6.4 \mathrm{~mm}$ and $108.9 \pm 27.3 \mathrm{~g}$ in August 2007 after 5 months conditioning. Neither their test diameter $(F=0.6338, d f=1,233, p=0.4268)$ nor wet weight $(F=0.8992, d f=1,233, p=0.344)$ varied from Constant Spring group 1 urchins when they were morphologically examined in August 2006, also after 5 month conditioning. Therefore Constant Spring group 1 and group 2 urchins can be considered morphologically identical.

\subsection{Fecundity}

An in-season spawning induction was performed for a portion of the wild (field) collected sea urchins in March 2006 to determine spawning condition, mature or spent, of animals to be conditioned; $17 \%$ of males and $52 \%$ of females could be induced to spawn at this time.

Inadequate access to wild urchins limited out-of-season spawning induction to only five individual urchins in November. No wild females ( 0 out of 2 ) and only one male ( 1 out of 3 ) would spawn in November. In January, of the 40 wild sea urchins injected with $\mathrm{KCl}$, $79 \%$ of the males and $14 \%$ of the females spawned. Due to the low number of wild gravid females in January, effective out-of-season spawning inductions were defined as all spawning from May to January and in-season spawning from February to April.

From November thru April $>90 \%$ of the males induced to spawn successfully released spermatozoa in the Constant Spring system.
Within the same system, only $70 \%$ of induced females spawned in November and $>90 \%$ spawned between December and April. When out-of-season induced spawning events were pooled, 93\% males and $85 \%$ females induced to spawn released gametes in the Constant Spring system group 1.

In the Advanced system, of the males injected with $\mathrm{KCl}, 91 \%$ spawned in November, $86 \%$ in December, and 100\% in January. Within the same system, only $13 \%$ of injected females spawned in November, $50 \%$ in December, and 100\% in January. When out-of-season spawning were combined, $91 \%$ males and $62 \%$ females were successfully induced to spawn in the Advanced system.

In August 2007, 100\% of males and females in the Constant Spring system, after both five (group 2) and eighteen months (group 1) conditioning, were induced to spawn. From the wild $60 \%$ of males and $10 \%$ females ( 1 out of 10 ) could be induced to spawn at this time.

Specific fecundity was calculated by dividing the volume of spawn $(\mathrm{ml})$ by the wet weight of the individual $(\mathrm{g})$. For conditioned females, specific fecundity was greater in all in-season spawning inductions compared to out-of-season $(F=7.668, d f=1,178, p=0.006)$ by an average of $0.038 \mathrm{ml} / \mathrm{g}$, approximately $30 \%$. There was also an effect of conditioning treatment on female specific fecundity $(F=25.874$, $d f=3,178, p<0.001$ ) (Fig. 2). There was no interaction between spawning date and treatment for specific fecundity. When all spawning induction dates are pooled, the Constant Spring groups had higher fecundity than the Advanced ( $p=0.013, p=0.048$ respectively) and wild ( $p<0.001, p<0.001$, respectively) groups. In addition, the Advanced group had higher specific fecundity than the wild group $(p<0.001)$. No difference was found between the two Constant Spring groups $(p=0.427)$. In males, specific fecundity was not affected by spawning induction date $(F=1.288, d f=1,177$, $p=0.258)$. Specific fecundity was affected by conditioning treatment $(F=10.498, d f=3,177, p<0.001$ ) (Fig. 3). The Constant Spring group $1(p<0.001)$ and the Advanced group had approximately $4 \times$ higher specific fecundity compared to the wild. No difference was found between Constant Spring group 1 and Advanced $(p=0.719)$, nor between Constant Spring group 2 and the wild $(p=0.999)$.

\subsection{Gamete viability and maternal/paternal effects}

The numbers of eggs per $\mathrm{ml}$ spawn, percent fertilization, and percent hatch was calculated for each conditioning treatment and pooled for in-season (February thru April) and out-of-season (May thru January) spawning inductions. The number of eggs per $\mathrm{ml}$ spawn did not significantly differ between treatments $(F=1.7353, d f=4,97$, $p=0.148$ ) nor between in-season and out-of-season spawning

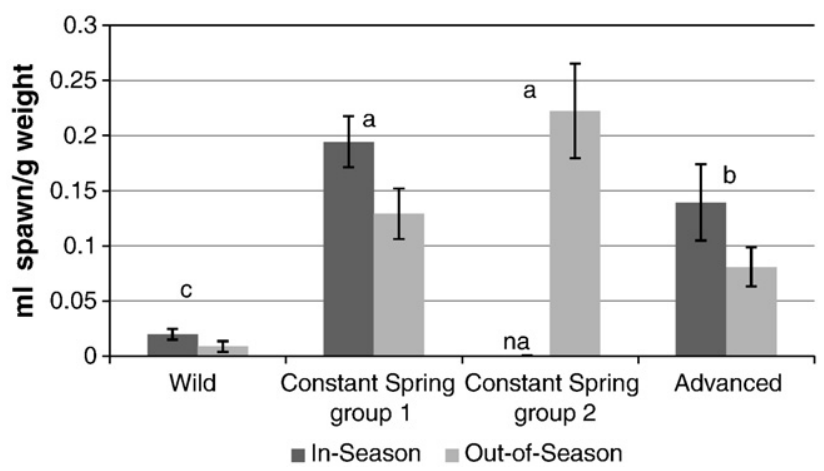

Fig. 2. Specific fecundity of female urchins (mean \pm SE). Specific fecundity was greater in all in-season spawning inductions compared to out-of-season for each treatment group. Different letters denote significant differences between treatment groups when in-season and out-of-season spawning inductions are pooled, at $p<0.05$. No interaction was found between treatment group and spawning date $(F=1.3193, d f=2,178$, $p=0.270$ ). 


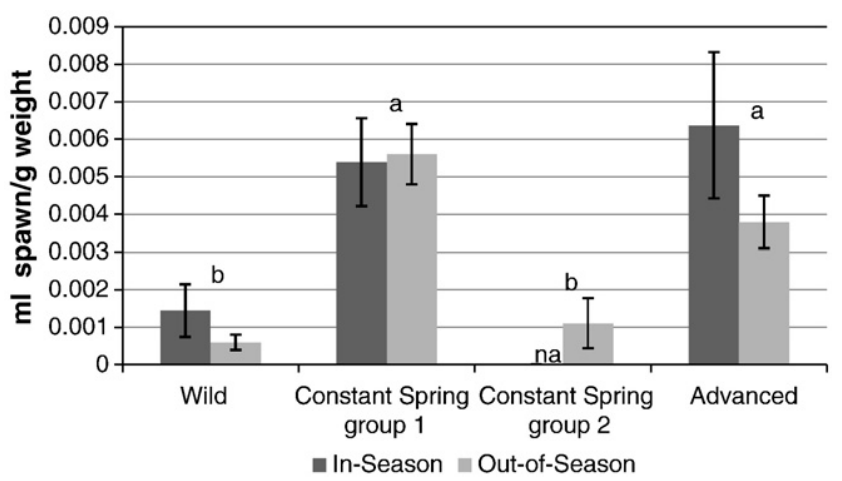

Fig. 3. Specific fecundity of male urchins (mean $\pm S E$ ). No difference was found between in-season and out-of-season spawning inductions. Different letters denote significant differences when in-season and out-of-season spawning inductions are pooled for each treatment group, at $p<0.05$. No interaction was found between treatment group and spawning date $(F=1.117, d f=2,177, p=0.330)$.

inductions ( $F=0.0606, d f=1,97, p=0.4381$ ) (Fig. $4 \mathrm{~A})$. There was no interaction between treatment and spawning date for the number of eggs per ml spawn $(F=1.305, d f=2,97, p=0.276)$. Fertilization success was not different between treatment groups $(F=1.643$, $d f=3,96, p=0.185)$, yet was affected by the seasonality of spawning induction $(F=11.446, d f=1,96, p=0.001)$. In-season spawning had a $10 \%$ higher fertilization rate than out-of-season spawning when all treatment groups were combined. (Fig. 4B). Hatching success was not different between conditioning treatments $(F=0.819, d f=3,89$, $p=0.487)$, but was affected by spawning induction date $(F=17.1862, d f=1,89, p<0.001)$. When all treatment groups are pooled, in-season spawning had a $19 \%$ higher hatching rate than outof-season spawning inductions (Fig. 4C).

Maternal and paternal effects on fertilization rate were calculated for six spawning events and a total of 16 females and 16 males. Maternal and paternal effects on hatching rate were also calculated, for five spawning events and a total of 14 females and 14 males. There was no paternal effect found on fertilization rate or hatching rate when examined for each of the five spawning events separately $(d f=5,30, p>0.5)$. Since no paternal effect was found, data could be pooled and compared for maternal effect on gamete viability. There was a significant maternal effect found for both fertilization and hatching rates $(F=9.8851, d f=13,34, p<0.001)$.

\subsection{Gonad indices}

Gonad weight of sea urchins changes in a polynomial fashion throughout the reproductive season, peaking at gametogenesis, and is the smallest just after spawning (Giese, 1966; Meidel and Scheibling, 1998b; Pearse and Cameron, 1991; Walker, 1982). Adjusted gonad weights (AGW) were analyzed over sample date, treatment, and sex. AGW was found to be influenced by date and conditioning treatment $(F=2.0415, d f=8,412, p=0.04053)$. The Constant Spring group 1 females were found to change over time $(F=2.276, d f=6,91$, $p=0.044)$, but not in a polynomial fashion as excepted with the natural reproduction cycle. Males did not change AGW over samples dates $(F=1.659, d f=7,110, p=0.127)$ (Fig. 5).

The Advanced females $(F=4.2523, d f=5,57, p=0.002)$ and males $(F=2.7027, d f=5,59, p=0.0418)$ were found to change over time in a polynomial fashion (Fig. 6). When peak gonad index was calculated using the trendline, gonad index peaked approximately 3 weeks earlier in males compared to females.

\subsection{NP diameters}

Nutritive phagocyte (NP) layer thickness is expected to cycle from maximum thickness in the summer just prior to gametogenesis to a
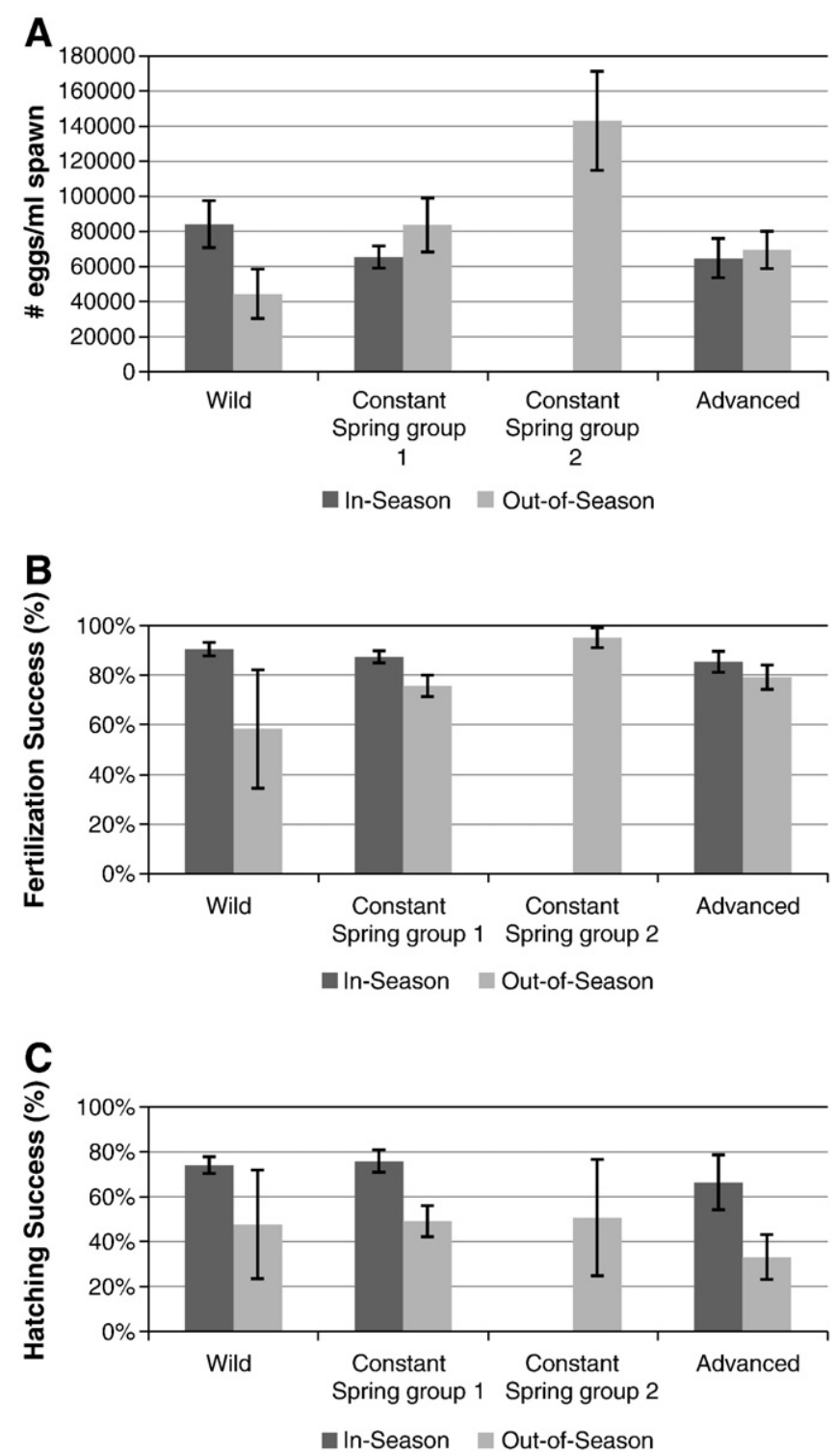

Fig. 4. (A) Number of eggs per ml spawn. (B) Fertilization rate of gametes released via KCL injection. (C) Hatching rate of gametes released via KCL induction. For both fertilization and hatching rates, in-season spawning was higher compared to out-ofseason for all treatments (mean $\pm \mathrm{SE}$ ).

minimum at spawning (Walker et al., 1998). Females on average were found to have a $39.01 \mu \mathrm{m}$ thicker NP layer than males regardless of treatment group or sample date $(F=26.1696, d f=1,67, p<0.001)$. Therefore sexes were separated for analysis. In the Constant Spring group 1 females, NP diameter was not different between sampling dates $(F=0.5788, d f=3,10, p=0.642)$. Males were found to cycle through the sampling dates $(F=3.8578, d f=4,19, p=0.019)$ with the largest NP layer occurring in August 2007 and the smallest in April 2007. Advanced females did significantly change NP thickness over sampling dates $(F=5.07, d f=2,9, p=0.033)$; with the largest NP layer occurring in October 2006 and the smallest in June 2006. Males did not change NP thickness over sampling dates $(F=0.5732$, $d f=2,11, p=0.5797)$.

\subsection{Oocyte diameters}

In histology it is difficult to tell where exactly in a spherical oocyte a slice is taken. Although measurements of diameter were limited to those histological samples with a visual nucleus, it is estimated that an 


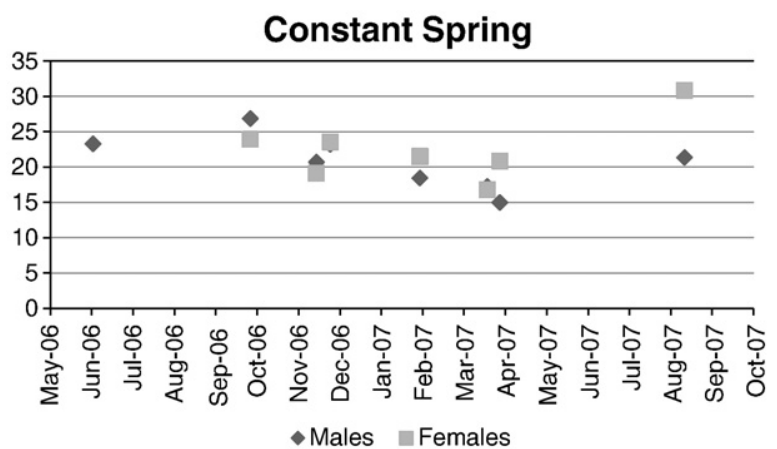

Fig. 5. Change in adjusted gonad weight (AGW) from September 2006 to May 2007 for the Constant Spring conditioned S. droebachiensis.

error of $\pm 10 \mu \mathrm{m}$ may be present in all measurements. Therefore, although, mature oocytes in S. droebachiensis are defined between 130 and $160 \mu \mathrm{m}$ in diameter (Falk-Petersen and Lønning, 1983), the range of maturity within this study was increased to include all diameters over $121 \mu \mathrm{m}$.

In the Constant Spring group 1 females, oocyte size-frequency showed a bimodal distribution with means of $87 \mu \mathrm{m}$ and $184 \mu \mathrm{m}$ $(n=4)$ in October, $46.4 \%$ of which being of mature size (mature defined between 121 and $160 \mu \mathrm{m}$ ). In December, there was no longer a bimodal distribution, with an average oocyte diameter of $62.28 \pm$ $3.36 \mu \mathrm{m}(n=6)$ and only $1 \%$ of mature size. Average oocyte diameter decreased to $17.98 \pm 1.92 \mu \mathrm{m}$ in April $2007(n=1)$ then increased in August $(63.93 \pm 3.62 \mu \mathrm{m})(n=4)$, with $0 \%$ of mature size for the April and August samples. No oocyte diameters were measured in June 2006. The Constant Spring group 2 females had an oocyte diameter average of $56.83 \pm 3.06 \mu \mathrm{m}$ with $0 \%$ at mature size in August 2007.

In the Advanced system, oocyte diameter increase from $26.46 \pm$ $1.95 \mu \mathrm{m}(n=1)$ in June $(=$ Nov. $)$ to $80.74 \pm 4.02 \mu \mathrm{m}(n=6)$ in October (=Jan.) then decreased to $66.44 \pm 2.06 \mu \mathrm{m}(n=5)$ in December (=Apr.). Only $14.1 \%$ of oocytes were mature in October and $0 \%$ were mature in June and December.

Samples in June and August from the wild did not yield any measureable oocytes (i.e. none of the oocytes had a visible nucleus). In October, $42.9 \%$ were of mature size at an average of $112.51 \pm 9.10 \mu \mathrm{m}$ $(n=1)$. In December, the average oocyte size decreased to $52.96 \pm$ $2.56 \mu \mathrm{m}(n=4)$, with $0 \%$ mature.

There were many samples which may have included mature oocytes, but could not be measured due to spontaneous spawning at

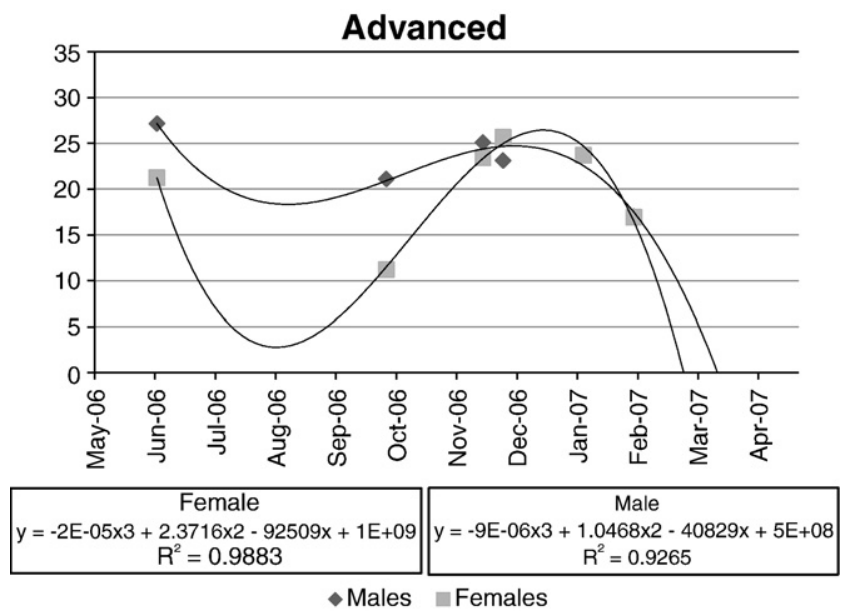

Fig. 6. Change in adjusted gonad weight (AGW) from September 2006 to May 2007 for the Advanced conditioned S. droebachiensis. dissection which caused mature oocyte to dissociate and at times leave a complete void within the gonad (Fig. 7).

\subsection{Stereology}

The relative volume of nutritive phagocytes (NP) should cycle inversely with the volume of germinal epithelium (GE) and gametes throughout the reproductive cycle (Harrington et al., 2007). In the Constant Spring group 1 females, relative volume of GE $(F=4.4104$ $d f=3,15, p=0.021)$ and gametes $(F=3.5433, d f=3,15, p=0.040)$ did significantly change between samples dates, yet relative volume of NP did not change $(F=1.396, d f=3,15, p=0.283)$. Males changed over time in the relative volume of gametes $(F=5.1593, d f=4,24$, $p=0.004)$, but not in volume of GE $(F=1.9036, d f=4,24, p=0.004)$ or NP ( $F=2.3164, d f=4,24, p=0.086$ ) over sample dates. Advanced females did not change significantly between sample dates in relative volume of $\mathrm{GE}(F=1.029, d f=2,8, p=0.4002)$, gametes $(F=2.7477$, $d f=2,8, p=0.1235)$ or NP $(F=2.0803, d f=2,8, p=0.187)$. Males also did not significantly change between sample dates for relative volume of $\mathrm{GE}(F=1.2565, d f=2,11, p=0.323)$, gametes $(F=3.7925$, $d f=2,11, p=0.056)$ or NP $(F=2.0803, d f=2,8, p=0.187)$.

\subsection{Reproductive staging}

Using histological samples, reproduction stage can be estimated for each sample according to the classification scheme of Walker et al. (2001). A portion of the Constant Spring group 1 females were found to cycle through all four stages of the reproductive cycle, but not all female samples showed evidence of cycling (Fig. 8A). Males in Constant Spring group 1 were found to be in the last two stages of reproduction every time they were sampled, therefore no evidence of reproductive cycling could be found. In the Advanced system, females were found to cycle through the various stages of reproduction collectively as a group (Fig. 8B). Males were found to exhibit changes in the proportion of the last two stages of the reproductive cycle, but this cannot be confirmed through histology that they went through a complete reproductive cycle.

\section{Discussion}

Modifying both photoperiod and temperature successfully altered gametogenic, and more specifically vitellogenic, cycling in the green sea urchin, S. droebachiensis allowing for year round collection of viable gametes.

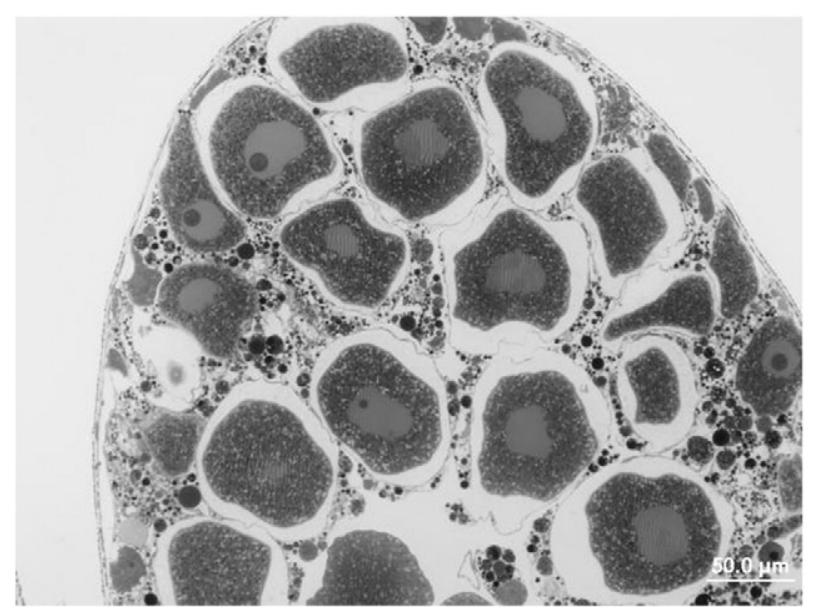

Fig. 7. Female histology section with evidence of spontaneous spawning and dissociated mature oocytes. 
A

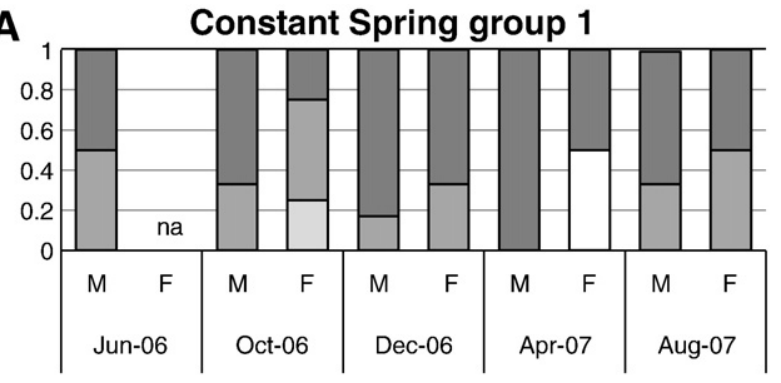

미 ㅁII ㅁII IV

\section{B}

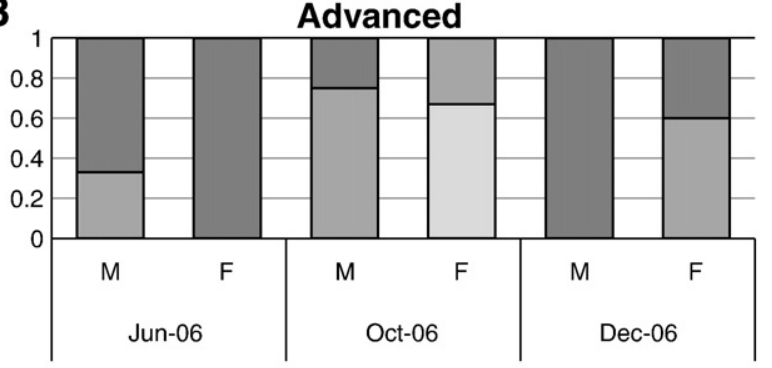

미 ㅁII ㅁII aIV

Fig. 8. Reproductive staging of (A) Constant Spring group 1 and (B) Advanced conditioned urchins, represented as proportion in each of the reproduction stages (Walker et al., 2001): (I) Inter-gametogenesis and NP phagocytosis, (II) pregametogenesis and NP renewal, (III) gametogenesis and NP utilization, and (IV) end of gametogenesis, NP exhaustion and spawning.

\subsection{Methodology}

The conditioning system design used in this experiment maintained water quality well within recommended limits (Basuyaux and Mathieu, 1999; Siikavuopio et al., 2004a,b, 2007a,b) and produced extremely high survival post acclimation. Prior gonad enhancement studies with S. droebachiensis reported far lower acclimation mortality (<5.6\% Minor and Scheibling, 1997; <6.1\% Pearce et al., 2002; <10\% Pearce et al., 2003; Siikavuopio et al., 2004a; 12-16\% Siikavuopio et al., 2007a; 10-15\% Siikavuopio et al., 2007b) noting the importance of short transportation time, maintaining a wet environment and reducing abrasion (Dale et al., 2005; Siikavuopio et al., 2007b). Therefore, high initial mortality may be attributed to the two hour delay in transportation, a chance of desiccation and abrasion within fish bins during transport. Survival was maintained although densities were $2 \times$ higher than recommended levels for $S$. droebachiensis (Siikavuopio et al., 2007a). The lack of significant growth may indicate too high a stocking density, though somatic growth of broodstock is not a priority of aquaculture operations, therefore not important to maintain. Luis et al. (2005) found stocking densities could be increased as high as $20 \mathrm{~kg} / \mathrm{m}^{2}$ in P. lividus broodstock conditioning systems. It is likely that broodstock densities could be maintained at an even higher level than in this study without impairing fecundity or survival. Lack of growth in test diameter has been similarly found in other studies of green sea urchins of this diameter (Harrington et al., 2007; Walker et al., 1998) and may be due to the asymptotic growth rate of urchins of this size (Lamare and Mladenov, 2000), not overcrowding.

The method of collecting and processing gonad samples for histology/stereology may have underestimated the presence of mature gametes due to the spontaneous release of mature gametes at dissection. Therefore measurements such as oocyte diameter and stereology may not be the best method to characterize the population's reproductive physiology at the time of maturation. In addition, using a sample size of ten individuals per treatment group per sample time is too small when sexes cannot be previously determined prior to sampling. This may lead to the underrepresen- tation of one sex, as occurred in this study at data number of sampling events. Cycling of cell types and reproductive staging through histology may be the best method to describe reproductive maturation in the green sea urchin due to previously described limitations. Even with the used of image analysis, an insufficient number of sampling dates was used in this study to sufficiently determine reproductive cycling within the conditioning populations. Analysis of reproductive cycling using histological and stereological techniques is intensive in time, sample sizes, and economically.

Urchins within this study had a higher gonad index than the wild for both males and females. Females averaged $4 \%$ and males $7 \%$ to $8 \%$ higher gonad index values than what would be expected from the wild after accounting for change over time. Previous studies found the same result as well as a smaller size at first maturity when laboratory reared urchins were compared to wild urchins (Pearse et al., 1986; Unuma et al., 1996). In addition, it has been observed that laboratory urchins exhibit delayed gametogenesis and a longer spawning duration than their wild counterparts (Unuma et al., 1996) due to environmental conditions within the laboratory such as increased food supply and decreased environmental stress (McBride, 2005).

\subsection{Out-of-season gamete production}

This study demonstrated that it is possible to obtain significant numbers of viable gametes year round with $S$. droebachiensis and with higher specific fecundity compared to the wild. In addition, eggs per $\mathrm{ml}$ spawn, percent fertilization, and percent hatch of out-ofseason produced gametes was equal to or surpassed levels reported in the wild. Although a 2 month advancement in the spawning season of S. droebachiensis has been reported prior (Stephens, 1972), viability of gametes was never proven. The increase in fecundity and viability of gametes spawned from the conditioned urchins compared to the wild may be due to increased availability of high quality food to broodstock within the laboratory.

A strong maternal effect on fertilization and hatch rates in green sea urchins demonstrates the importance of high quality female gametes to a commercial aquaculture business. The ability to determine the sex of an individual prior to conditioning and/or spawning would be economically valuable to the commercial development of the sea urchin industry in terms of broodstock management. Future studies should also examine the possibility of spawning broodstock more than once. This would significantly decrease the economic investment involved in gamete collection, in addition to allowing division of broodstock by sex.

\subsection{Suspension of gametogenesis}

Using Constant Spring photoperiod and temperature, mature broodstock can be conditioned out-of-season and induced to spawn within five months post-stocking. In addition, urchins can be maintained in a ripe condition for 18 months, actually improving in the number of viable offspring produced per volume of spawn overtime. High volume spawns are desired within aquaculture due to the reduced cost per gamete (Luis et al., 2005). Additional research needs to be completed to determine the speed of maturation induction using spring conditions using field collected urchins at different times of the year. Research by Luis et al. (2005) determined that $P$. lividus reproductive maturation could be induced in wild collected urchins through Constant Spring conditions as early as 60 days post conditioning. In addition, if broodstock are to be spawned more than once, the amount of time needed to recover would need to be investigated. Maturation longevity beyond eighteen months would not be necessary in aquaculture due to the high holding cost, unless selective breeding can be demonstrated as economical. 
Some cycling may have occurred in this system; evidenced by a changing AGW, and evidence of some reproductive cycling for females. When oocyte diameters were measured, the Constant Spring females were found to possess two cohorts of oocyte diameters, both mature and immature oocytes, in October. This may be an artifact of the stocking population, approximately half of which were spent. If this is the case, then the act of spawning, not autumnal equinox (Dumont et al., 2006; Walker et al., 1998), may be the trigger for initiating gametogenesis/vitellogenesis in S. droebachiensis.

Although gametes could be collected in August after eighteen months of conditioning, approximately six months out-of-season with the wild, change in reproductive staging and nutritive phagocyte thickness suggests some possible cycling past the spawning stage. It is possible that after one year of suspending gametogenesis, gametes were partially reabsorbed and gametogenesis occurred continuously thereafter. The effect of the low stress and good husbandry practices and nutritional intake used in this experiment must also be considered.

\subsection{Gametogenesis advancement}

In addition to suspending gametogenesis, advancing gametogenesis and vitellogenesis was also achieved through manipulation of photoperiod and temperature. Although the goal of this portion of the experiment was to advance the reproduction cycle by six months, viable gametes could not be produced in large number earlier than 9 months. A study by Walker et al. (1998), which applied an Advanced photoperiod to green sea urchins, suggested it was the autumnal equinox which initiates a new gametogenic cycle in this species. Due to previously described limitations of the histological and stereological methods used in this study, it may be possible that photoperiod manipulation alone and not the combination of both photoperiod and temperature manipulation, is required to initiate gametogenesis in the green sea urchin.

The lack of changes in adjusted gonad weights and cell type volumes evident in this treatment group may be an artifact of the sampling schedule and not because gametogenesis did not occur. Spawning inductions, NP thicknesses, oocyte diameter measurements, and histological staging data confirm that cycling indeed occurred for both males and females under Advanced photoperiod and temperature. After analyzing AGW and spawning data, it can be inferred that the females lag behind males by 3 weeks in reproductive cycling. This may be due to the large reproductive effort required from females compared to males. This finding has implications for ecological management of the green sea urchin fishery.

\section{Conclusion}

This experiment produced several novel pieces of information regarding green sea urchin, S. droebachiensis reproduction physiology: (1) viable gametes may be collected year round through photoperiod and temperature manipulation; (2) gametogenesis and vitellogenesis may both be suspended and advanced by up to nine months through manipulation of photoperiod and temperature; (3) there is a significant maternal effect on both fertilization and hatch rates; (4) females lag behind males in maturation of gametes by approximately three weeks; and (5) gametogenesis in females may be initiated by prior spawning activity, as well as through environmental parameters such as the autumnal equinox.

Although an additional energy cost would be incurred by maintaining a photoperiod and temperature regime different from the natural environment, the economic benefit from an efficient use of hatchery resources should outweigh the cost. Using a Constant Spring photoperiod and temperature, males and females containing large numbers of mature gametes can be maintained over eighteen months. Using an Advanced six month annual photoperiod and temperature cycle, both males and females can go through a complete reproductive cycle, from spent to mature, in three months less time than occurs in the wild. The coupling of the two different photoperiod and temperature regimes, Constant Spring and Advanced, may increase the spawning potential of each individual urchin to several times per year, reducing potential size, therefore cost, of a broodstock maintenance system. Year round hatchery production, not just outof-season, may be a better economic solution for green sea urchin aquaculture.

\section{Acknowledgements}

Funding for this research came from the United States Department of Agriculture Small Business Innovative Research grant (SBIR), the Maine Aquaculture Innovation Center, and the Department of Industrial Cooperation at the University of Maine. The authors would like to thank Jim Wadsworth of Friendship International, Dr. Chuck Walker and Anne Böttegar of the University of New Hampshire, Dr. Kelly Edwards of the University of Maine, and the Center for Cooperative Aquaculture Research staff for all their assistance.

\section{References}

Basuyaux, O., Mathieu, M., 1999. Inorganic nitrogen and its effects on growth of the abalone Haliotis tuberculata Linnaeus and the sea urchin Paracentrotus lividus Lamarck. Aquaculture 174, 95-107.

Bay-Schmidt, E., Pearse, J.S., 1987. Effect of fixed day lengths on photoperiodic regulation of gametogenesis in the sea urchin Strongylocentrotus purpuratus. International Journal of Invertebrate Reproduction and Development 11, 287-294.

Cocanour, B., Allen, K., 1967. The breeding cycles of a sand dollar and a sea urchin. Biochemical Physiology 20, 327-331.

Dale, T., Siikavuopio, S., Aas, K., 2005. Roe enhancement in sea urchin: effects of handling during harvest and transport on mortality and gonad growth in Stronglyocentrotus droebachiensis. Journal of Shellfish Research 24 (4), 1235-1239.

Dumont, C.P., Himmelman, J.H., Robinson, S.M.C., 2006. Random movement pattern of the sea urchin Strongylocentrotus droebachiensis. Journal of Experimental Marine Biology and Ecology 340, 80-89.

Ebert, T.A., 1968. Growth rates of the sea urchin Strongylocentrotus purpuratus related to food availability and spine abrasion. Ecology 49, 1075-1091.

Falk-Petersen, I.B., Lønning, S., 1983. Reproductive cycles of two closely related sea urchin species, Strongylocentrotus droebachiensis (O.F. Muller) and Strongylocentrotus pallidus (G.O. Sars.). Sarsia 68, 157-164.

Fuji, A.R., 1967. Ecological studies on the growth and food consumption of Japanese common littorial sea urchin Strongylocentrotus intermedius. Bulletin of the Fisheries, vol. 11. Faculty of Hokkaido University, pp. 49-87.

Giese, A.C., 1959. Reproductive cycles of some west coast invertebrates. Photoperiodism and related phenomena in plants and animals. American Association for the Advancement of Science, Washington, D.C., USA, pp. 625-638.

Giese, A.C., 1966. Changes in body component indexes and respiration with size in purple sea urchin Strongylocentrotus purpuratus. Physiological Zoology 40, 194-200.

Harrington, L.H., Walker, C.M., Lesser, M.P., 2007. Stereological analysis of nutritive phagocytes and gametogenic cells during the annual reproductive cycle of the green sea urchin, Strongylocentrotus droebachiensis. Invertebrate Biology 126, 202-209.

Harris, L.G., Madigan, P., Waters, K., 2003. A hatchery system for green sea urchin aquaculture in the Gulf of Maine. World Aquaculture 34, 32-36.

Himmelman, J.H., 1978. Reproductive cycle of the green sea urchin, Strongylocentrotus droebachiensis. Canadian Journal of Zoology 56, 1828-1836.

Kirchhoff, N.T., Eddy, S., Harris, L., Brown, N.P., 2008. Nursery-phase culture of green sea urchin Strongylocentrotus droebachiensis using "on-bottom" cages. Journal of Shellfish Research 27, 921-927.

Lamare, M.D., Mladenov, P.V., 2000. Modelling somatic growth in the sea urchin Evechinus chloroticus (Echinoidea: Echinometridae). Journal of Experimental Marine Biology and Ecology 243, 17-43.

Larson, B.R., Vadas, R.L., Keser, M., 1980. Feeding and nutritional ecology of the sea urchin Strongylocentrotus droebachiensis in Maine, USA. Marine Biology 59, 49-62.

Lemire, M., Himmelman, J.H., 1996. Relation of food preferences to fitness for the green sea urchin, Strongylocentrotus droebachiensis. Marine Biology 127, 73-78.

Luis, O., Delgado, F., Gago, J., 2005. Year-round captive spawning performance of the sea urchin Paracentrotus lividus: relevance for the use of its larvae as live feed. Aquatic Living Resources 18, 45-54.

McBride, S.C., 2005. Sea urchin aquaculture. American Fisheries Society Symposium 46, 179-208.

McClintock, J., Watts, S., 1990. The effects of ambient water temperature ranges between $19-22^{\circ} \mathrm{C}$ of photoperiod on gametogenesis on the tropical sea urchin Eucidaris tribuloides. Journal of Experimental Marine Biology and Ecology 139, 175-184. 
Meidel, S.K., Scheibling, R.E., 1998a. Size and age structure of the sea urchin Strongylocentrotus droebachiensis in different habitats. In: Mooi, R., Telford, M. (Eds.) Echinoderms: San Francisco. Balkema, Rotterdam, The Netherlands, pp. 737-742.

Meidel, S.K., Scheibling, R.E., 1998b. The annual reproductive cycle of the green sea urchin Strongylocentrotus droebachiensis, in differing habitats in Nova Scotia, Canada. Marine Biology 18, 99-114.

Minor, M.A., Scheibling, R.E., 1997. Effects of food ration and feeding regime on growth and reproduction of the sea urchin Strongylocentrotus droebachiensis. Marine Biology 129, 159-167.

Munk, J.E., 1992. Reproduction and growth of sea urchins Strongylocentrotus droebachiensis (Muller) near Kodiak, Alaska. Journal of Shellfish Research 11, 245-254.

Oganesyan, S.A., 1998. Reproductive cycle of the echinoid Strongylocentrotus droebachiensis in the Barents Sea. In: Mooi, R., Telford, M. (Eds.), Echinoderms: San Francisco. Balkema, Rotterdam, The Netherlands, pp. 765-768.

Palmer, L., 1937. The shedding reaction in Arbacia punctulata. Physiological Zoology 10 352-367.

Pearce, C.M., Daggett, T.L., Robinson, S.M.C., 2002. Optimizing prepared feed ration for gonad production of the green sea urchin Strongylocentrotus droebachiensis. Journal of the World Aquaculture Society 33, 268-277.

Pearce, C.M., Daggett, T.L., Robinson, S.M.C., 2003. Effect of starch type, macroalgal meal source, and beta-carotene on gonad yield and quality of the green sea urchin, Strongylocentrotus droebachiensis (Muller), fed prepared diets. Journal of Shellfish Research 22, 2505-2519.

Pearse, J.S., Cameron, R.A., 1991. Echinodermata: Echinoidea. In: Giese, A.C., Pearse, C.M. (Eds.), Reproduction of marine invertebrates. : Echinoderms and Lophophorates, VI. The Boxwood Press, Pacific Grove, CA, USA, pp. 514-662.

Pearse, J.S., Pearse, V.B., Davis, K.K., 1986. Photoperiodic regulation of gametogenesis and gonadal growth in the sea urchin Strongylocentrotus purpuratus. Journal of Experimental Zoology 237, 107-118.

Sakairi, K.M., Yamamoto, K., Ohtsu, M., Yoshida, M., 1989. Environmental control of gonadal maturation in laboratory reared sea urchins, Anthocidaris crassispina and Hemicentrotus pulcherrimus. Zoological Sciences 6, 721-730.

Siikavuopio, S.I., Dale, T., Foss, A., Mortensen, A., 2004a. Effects of chronic ammonia exposure on gonad growth and survival in the green sea urchin, Strongylocentrotus droebachiensis. Aquaculture 242, 313-320.

Siikavuopio, S.I., Christiansen, J.C., Dale, T., Nevermo, I., 2004b. Effects of chronic nitrite exposure on gonad growth and survival in green sea urchin, Strongylocentrotus droebachiensis. Aquaculture 242, 357-363.

Siikavuopio, S.I., Dale, T., Mortensen, A., 2007a. The effects of stocking density on gonad growth, survival and feed intake of adult green sea urchin (Strongylocentrotus droebachiensis). Aquaculture 262, 78-85.
Siikavuopio, S.I., Dale, T., Mortensen, A., Foss, A., 2007b. Effects of hypoxia on feed intake and gonad growth in the green sea urchin, Strongylocentrotus droebachiensis. Aquaculture 266, 112-116.

Stephens, R.E., 1972. Studies on the development of the sea urchin Strongylocentrotus droebachiensis. I. Ecology and normal development. Biological Bulletin 142, 132-144.

Strathmann, R., 1978. Length of Pelagic period in echinoderms with feeding larvae from the northeast Pacific. Journal of Experimental Marine Biology and Ecology 34, 23-27.

Thompson, R.J., 1982. The relationship between food ration and reproductive effort in the green sea urchin Stongylocentrotus droebachiensis. Oecologia 56, 50-57.

Unuma, T., Konishi, K., Furita, H., 1996. Seasonal changes in the gonads of cultured and wild Pseudocentrotus depressus. Journal of Suisan Zoshoku 44 (2), 169-175.

Vadas, R.L., 1977. Preferential feeding: an optimization strategy in sea urchins. Ecological Monograph 47, 337-371.

Vadas, R.L., Beal, B.F., 1999. Temporal and spatial variability in the relationships between adult size, maturity, and fecundity in green sea urchins: the potential use of roe-yield standard as a conservation tool. Report to the Maine Department of Marine Resources, $136 \mathrm{pp}$.

Vadas, R.L., Beal, B., Dudgeon, S., Chamberlain, B., Baxter, B., 1989. The reproductive biology of green sea urchins on the coast of Maine, Interim Report: Maine Cooperative Extension Service, p. 34

Walker, C.M., 1980. Spermatogenic columns, somatic cells and the microenvironment of germinal cells in the testes of asteroids. Journal of Morphology 162, 81-107.

Walker, C.M., 1982. Nutrition of gametes. In: Jangoux, M., Lawrence, J.M. (Eds.), Echinoderm nutrition. A.A. Balkema, Rotterdam, The Netherlands, pp. 449-468.

Walker, C.M., Lesser, M.P., 1998. Manipulation of food and photoperiod promotes outof-season gametogenesis in the green sea urchin, Strongylocentrotus droebachiensis: implications for land-based aquaculture. Journal of Shellfish Research 17, 340.

Walker, C.M., Unuma, T., McGinn, N.A., Harrington, L.M., Lesser, M.P., 2001. Reproduction of sea urchins. In: Lawrence, J.M. (Ed.), Edible Sea Urchins: Biology and Ecology. Elsevier Science B.V, pp. 5-26.

Walker, C.M., Harrington, L.H., Lesser, M.P., Fagerberg, W.R., 2005. Nutritive phagocyte incubation chambers provide a structural and nutritive microenvironment for germ cells of Strongylocentrotus droebachiensis, the green sea urchin. Biological Bulletin 209, 31-48.

Yamamoto, M., Ishine, M., Yoshida, M., 1988. Gonadal maturation independent of photic conditions in laboratory-reared sea urchins, Pseudocentrotus depressus and Hemicentrotus pulcherrimus. Zoological Sciences 5, 979-988. 